\title{
The Psychological General Well-Being Index (PGWBI) for assessing stress of seafarers on board merchant ships
}

\author{
Anna Carotenuto ${ }^{1,2}$, Angiola M. Fasanaro², Ivana Molino ${ }^{1,2}$, Fabio Sibilio ${ }^{3}$, \\ Andrea Saturnino $^{3}$, Enea Traini ${ }^{1}$, Francesco Amenta ${ }^{1,3}$ \\ ${ }^{1}$ Centre for Clinical Research, Telemedicine and Telepharmacy, University of Camerino, Camerino, Italy \\ ${ }^{2}$ Neurology Unit, National Hospital, "A. Cardarelli", Naples, Italy \\ ${ }^{3}$ Department of Study and Research, International Radio Medical Centre (CIRM), Rome, Italy
}

\begin{abstract}
Background: In their working activity, seafarers are exposed to high levels of stress that should be accurately investigated, measured, followed up and, if possible, countered. This is also required by regulations recently entered into force such as the Maritime Labour Convention 2006, recommending to consider special physiological or psychological problems created by the shipboard environment. The choice of the tools for this evaluation is challenging, and a common basic standard usable in a large scale should be identified. Aim: The aim of this study was to evaluate: 1) the suitability of the Psychological General Well-Being Index (PGWBI) questionnaire conducted on board for assessing stress in the sailing seafarers, 2) The presence of stress in seafarers of different categories (deck officers, engine officers, deck crew, engine crew, chief stewards/catering staff) monitored by the PGWBI.

Materials and methods: 162 male seafarers on board of 7 tankers belonging to the same shipping company were evaluated through the PGWB questionnaire. Analysis of variance (ANOVA) was used to analyse the differences in the scores of the questionnaire.

Results: Engine officers exhibited significantly higher anxiety levels than the deck or engine crew, and showed lower satisfaction than the deck crew. Deck and engine officers revealed higher self-control levels than the engine crew. Chief stewards/catering staff showed lower vitality levels than the deck crew.

Conclusions: Deck or engine officers should achieve a greater self-control than the crew and this is documented by the present study. Our findings support the view that management responsibility is more often associated with higher levels of stress. In our opinion, the PGWB questionnaire is a reasonable compromise for obtaining a global evaluation of psychological conditions, including stress of seafarers. It should be therefore considered as a large scale tool for assessing the well-being and eventual stress levels of sailing seafarers.
\end{abstract}

(Int Marit Health 2013; 64, 4: 215-220)

Key words: seafarers, stress, on board evaluation, Psychological General Well-Being Index

\section{INTRODUCTION}

Stressful factors are known to contribute to a wide spectrum of diseases. Occupational activity represents the cause of distress in 25\% of cases [1-4]. Among different activities, seafaring is characterised by particularly high levels of stress, as highlighted by previous [5-7] and more recent studies $[8,9]$. Stressful factors associated with seafaring constitute therefore a relevant problem that should be known and countered [8, 9].

Stressful factors have been divided into objective and subjective [10]. Objective stress factors for seafarers are represented by the specific conditions entailed by working

Francesco Amenta, Centre for Clinical Research, Telemedicine and Telepharmacy, University of Camerino, Via Madonna delle Carceri, 9, 62032 Camerino, Italy, e-mail: FAmenta@gmail.com 
on ships. Subjective stress factors are related to the intrinsic characteristics of the subjects. Objective factors include noise and vibrations caused by engines, sleep disturbances due to them and to turn ship, as well as the long separations from families. Ship organisation, duties and responsibilities also fit into the objective factors. Subjective factors are those depending from the personality of each worker, and are related to his attitude to face stressful conditions, to find satisfaction with job, to be resilient, etc. All these aspects contribute to the capacity of each employee to cope with possible dangerous circumstances during his work as physical accidents and psychological troubles [11-14].

The psychological well-being of the seafarers is a relevant problem, as depression and suicide have been reported in these workers by numerous studies [15-21]. Analysis from 1960 to 2009 on the deaths by seafarers compared to the total deaths of 17,026 show 1,011 seafarers died as a result of a suicide (5.9\%). Compared to the deaths of 4,487 seafarers due to illnesses, 590 of them died as a result of a suicide (13.1\%) [22].

In view of the above risks, psychological health of people working at sea should be accurately investigated, measured, followed up and possibly countered. It is also important to evaluate the role played by each stressor. This evaluation, which allows to plan and put in practice prevention measures, is also required by some countries. On the other hand, regulations recently entered into force, such as the Maritime Labour Convention 2006 [23], recommend to consider special physiological or psychological problems created by the shipboard environment. The choice of the tools for this evaluation is challenging, and a common basic standard for large scale studies should be identified. For the proper analysis, stress of the seafarers should be assessed when they are at sea, where it is almost impossible to interview workers directly. Hence, the only possibility is to administer them a questionnaire that they should complete when they are on board. Any questionnaires should be chosen taking into account wide differences of the seafarers population in terms of education, nationality and cultural background.

The main aim of this study was to evaluate the suitability of the Psychological General Well-Being Index (PGWBI) questionnaire [24] as a stress measure among seafarers. This questionnaire was chosen, as it provides a psychological profile of the stress perceived, and is widely employed in stress evaluations. It also assesses several aspects that are known as important causes of stress in seafarers, such as sleeping difficulties, depression, fatigue, loneliness, state of tension, possible conflicts on board, monotony, no perspectives of development, and the necessity to take difficult decisions [10]. The questionnaire was made on board under the supervision of remote psychologists. The PGWBI questionnaire was also used to evaluate the presence of stress in seafarers of different categories (deck officers, engine officers, deck crew, engine crew, chief stewards/ /catering staff).

\section{MATERIALS AND METHODS}

\section{SUBJECTS}

The study group consisted of 162 male seafarers (1 Argentine, 1 Bulgarian, 122 Indians, 37 Italians and 1 Romanian) on board of 7 tankers belonging to the same shipping company (Finaval Group, Rome, Italy). Among the population investigated, 2 subjects were on board from less than 2 weeks when the questionnaires were proposed and were therefore excluded from the present analysis. The PGWBI questionnaire was sent on board together with instructions and extensive explanations on how to administer it between August 2012 and April 2013. Captains of the ships were trained to the questionnaire administration and used as a reference point in case any clarification was required from the single seafarers. The test was sent on board 1 week before the visit of the medical team for occupational medicine duties. Crew members answered to the questionnaire while being on board and were required to fill it in the day before the occupational medicine check-up. Two versions were available - Italian and English - and interviewed people could choose the language they felt more familiar. Filled-in questionnaires were returned by seafarers to a physician at the moment present on board for occupational medicine duties. This physician besides performing medical check-ups, interviewed each seafarer about the PGWBI questionnaire. Filled-in questionnaires were then collected in different envelops -1 for each group of the investigated seafarers. The test was anonymous and subjects were required to indicate only their age and generic rank according to the categories listed in Table 1. The response rate was $100 \%$. The mean age of the sample was 34.9 years $(S D=11)$, which is the average age of the seafarers across the organisation. The distribution of the subjects in the different occupational groups is summarised in Table 1.

\section{QUESTIONNAIRE}

The PGWBI questionnaire, which includes 22 items, allows to measure stress level by self-perceived evaluation [24]. PGWBI has been validated and is used in many countries in large populations and specific groups studies. In 2000 the PGWBI was validated in a representative sample of 1,129 Italian citizens aged from 15 years, and its normative values are available [24]. Questions cover 6 aspects: anxiety, depressed mood, positive well-being, self-control, general health and vitality. Each scale includes 3-5 items. Questions allow multiple choice answers with scores ran- 
Table 1. Number of subjects and mean age of different occupational groups

\begin{tabular}{llll}
\hline Group & Number of subjects & Mean age (SD) & Marital status \\
\hline Deck officers & 39 & $32.12(11.3)$ & Single $43 \%$ \\
Engine officers & 33 & $35.65(10.2)$ & Single $27 \%$ \\
Deck crew & 40 & $31.67(11.7)$ & Single $51 \%$ \\
Engine crew & 35 & $41.27(11.1)$ & Single $65 \%$ \\
Chief stewards/catering staff & 15 & $38.6(10.66)$ & Single $18 \%$
\end{tabular}

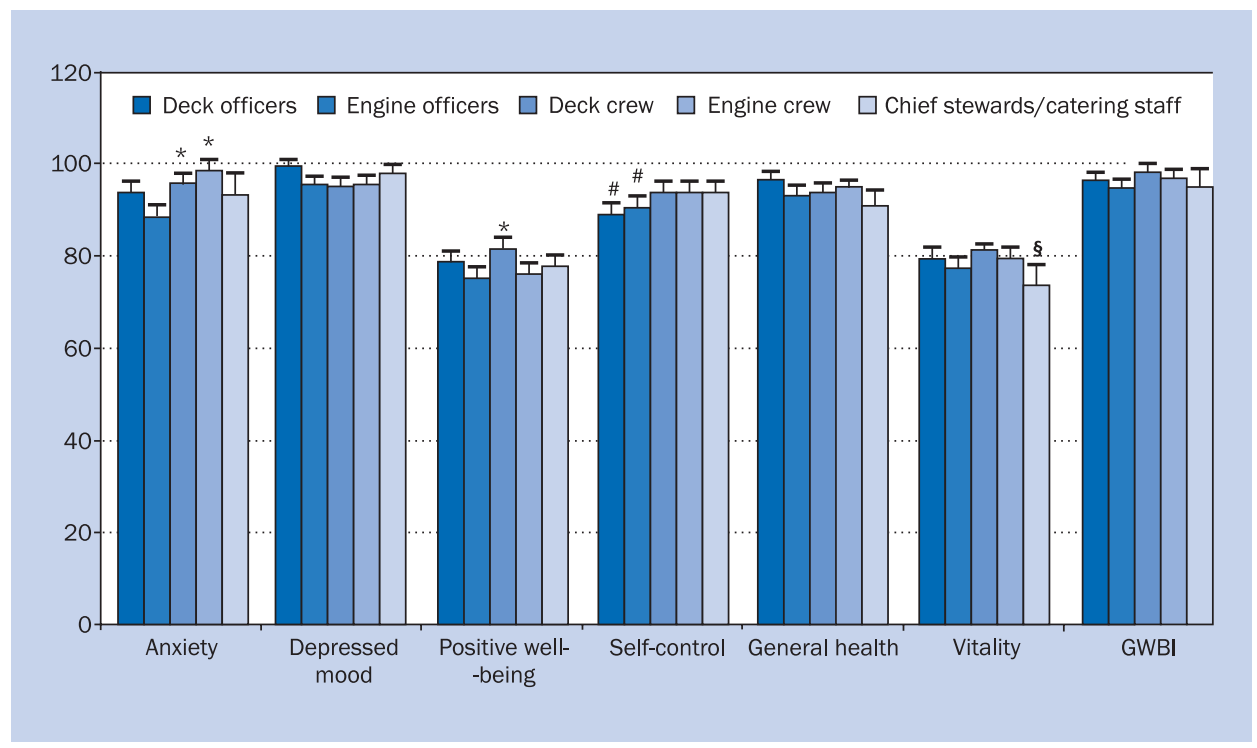

Figure 1. Scores obtained in the 6 scales by different categories of workers were compared using Between-Subjects One-Way Analysis of variance (ANOVA). The data are the mean \pm standard error; *significantly different at the ANOVA test with $p<0.05$ vs. engineer officers; \#significantly different at the ANOVA test with $p<0.05$ vs. engine crew; §significantly different at the ANOVA test with $\mathrm{p}<0.05$ vs. deck crew; GWBI - General Well-Being Index

ging from 0 to 5 (best score value). The PGWBI global score represents the sum of all items and ranges from 0 to 110. Higher scores indicate greater psychological well-being.

\section{DATA ANALYSIS}

Descriptive statistical analysis was carried out by calculating the means and standard deviations of the variables. Scores obtained in the 6 scales by different categories of workers were compared using Between-Subjects One-Way Analysis of variance (ANOVA).

\section{RESULTS}

All subjects answered to the questionnaire regardless of age, nationality and category. In the interview during the questionnaire delivery, it was unanimously reported that the questionnaire is easy and rapid, taking no more than 10-15 min to be completed. Results on each of the different domains covered by the questionnaire are reported below.

\section{ANXIETY}

Anxiety is related to the perception of tension and worry. A significant difference $(p<0.05)$ was found between deck crew and engine officers, and between engine crew and engine officers. Engine officers showed the lowest scores (more anxiety). The comparison between the groups revealed that deck crew and engine crew have higher scores (less anxiety) than other groups (Fig. 1).

\section{DEPRESSED MOOD}

Depression is a state of low mood and feelings of sadness and despair. It can be caused also by sleep disturbances and fatigue. Severe depression could represent a condition of risk of a suicide. In questions exploring mood, the lowest scores (presence of depression) were observed in deck crew, and the highest in the deck officers (no depression) (Fig. 1). However, the comparison between the groups did not show statistically significant differences. 
Table 2. Comparison of the General Well-Being Index within different groups of seafarers

\begin{tabular}{llllll} 
& Deck officers & Engine officers & Deck crew & Engine crew & $\begin{array}{l}\text { Chief stewards/ } \\
\text { /catering staff }\end{array}$ \\
\hline Well-being & $67 \%$ & $73 \%$ & $80 \%$ & $80 \%$ & $73 \%$ \\
No stress & $30 \%$ & $21 \%$ & $20 \%$ & $14 \%$ & $13 \%$ \\
Moderate stress & $0 \%$ & $3 \%$ & $0 \%$ & $3 \%$ & $13 \%$ \\
Severe stress & $3 \%$ & $3 \%$ & $0 \%$ & $3 \%$ & $0 \%$
\end{tabular}

\section{POSITIVE WELL-BEING}

Positive well-being refers to the satisfaction from working life and interest in the everyday activities. Obtained data showed a significant difference $(p<0.05)$ between deck crew and engine officers (Fig. 1). Engine officers recognise their work at sea as more unsatisfactory than the other groups, whereas deck crew showed the highest scores. The above differences were not significant from a statistical point of view.

\section{SELF-CONTROL}

Self-control refers to the ability to control one's emotions, behaviour, desires, self-confidence and the necessity to take difficult decisions. Significant differences were noticeable between deck and engine officers versus the engine crew (Fig. 1). The lowest scores in self-control (less self-control) were obtained by deck and engine crews.

\section{GENERAL HEALTH}

The general health section of the questionnaire assesses the perception of being in good health. It measures the worry of being ill and/or the feeling of excessive fatigue that may hinder the job. Deck officers obtained higher scores on this dimension (Fig. 1), but differences among groups were not statistically significant. No differences were found between the remaining 4 categories.

\section{VITALITY}

This dimension assesses the mental and physical fatigue, apathy, loss of energy, and possible sleep disorders. A significant difference $(p<0.05)$ was found between chief stewards/catering staff and deck crew (Fig. 1). The lowest scores (less vitality) were found in chief stewards/catering staff, and the highest ones in the deck crew.

\section{GENERAL WELL-BEING INDEX (GWBI)}

The comparison of the results of the overall index of well -being (GWBI) between the groups did not show significant differences (Fig. 1). All categories obtained scores falling within the areas of no-stress and/or well-being.

Comparison for groups analysis showed that more than the half of each group obtained a total score falling in the "well being" area (Table 2). 30\% of deck officers, $21 \%$ of engine officers, $20 \%$ of deck officers, $14 \%$ of engine officers and $13 \%$ of chief stewards/catering staff obtained a GWBI falling in the "no stress" area. 3\% of deck/engine officers and engine crew were in an obvious state of distress, a condition from which deck crew and chief stewards/catering staff did not suffer. $3 \%$ of engine officers and engine crew, and $13 \%$ of chief stewards and catering staff revealed a condition of moderate distress.

\section{DISCUSSION}

Seafarers are exposed to stressful conditions, some inevitably related to their activity (noise, vibrations, interrupted sleep, etc), and other more subjective (individual capacity to endure loneliness, attitude to resilience, etc). Both aspects may impact their capacity to cope with work and may lead to psychological distress. This issue is relevant as mental health disturbances have been reported frequently in seafarers, a category with higher risk of severe consequences compared to other activities [25]. Despite the recognised relevance of stress as a cause of diseases and accidents in maritime navigation, maritime field studies were focused primarily on fatigue and watch systems as univariate parameters [26], and the majority of attention was centered on physical rather than on mental stress.

More than the half of each group obtained a total score falling in the "well being" area, and 3\% of deck/engine officers and engine crew were in an obvious state of severe stress.

It is necessary to consider stress and psychological aspects of seafaring not only for ethical reasons or research purposes, but also for complying with incoming regulations. This is the case of the Maritime Labour Convention 2006 (see introduction) [23] and of Italian regulations to enter into force (e.g. the extension to the maritime compartment of the Legislative Decree No. 81 of 2008) [27]. For putting these regulations into practice, reliable and standard measures of work-related stress of seafarers should be available. So far no validated measures have been proposed to measure and follow up these features for seafarers in the context of a risky activity involving individuals of different nationalities, languages and education. 
The aim of this work was to test the feasibility of the questionnaire that could cover the most important aspects of work-related stress easily understandable and fillable by the seafarers while being on board. The proper stress assessment could allow to plan effective prevention measures of distress and, if necessary, to provide support and assistance. Our analysis has involved 162 seafarers who were required to answer to the questions not before than 2 weeks after the departure. Anonymity was guaranteed in any phase of the study to obtain sincere answers as much as possible.

The PGWBI questionnaire was selected on the basis of data on the topic emerging from literature [8, 9, 26]. The relevance of some psychological symptoms (anxiety, depression, insomnia, perception of being in poor health) in seafarers is widely accepted. The association between psychological distress and chronic fatigue, sleep disorders and energy loss is established as well [25]. The relationship between the above aspects is bidirectional, as the symptoms may be both the source and the consequence of psychological distress [25, 28]. Moreover, an increasing number of studies highlight that modern shipping industry and the globalisation requests have introduced relevant changes in this profession, leading to a global burden apparently increasing year after year [29]. The availability of a well-defined and detailed tool, which could help to measure, with objectivity, the psychological consequences of the seafaring, is therefore required. It is also important to understand if the global index of the perceived stress varies within the different seafarers categories.

The questionnaire we have proposed has demonstrated to be easy, understandable, and rapid, as all seafarers (100\% response rate) answered in 10-15 min. Results showed differences in the levels of stress between different categories. Engineer officers reported significantly higher anxiety levels than the engine and deck crews. Engine officers showed lower satisfaction than deck crew, suggesting that the higher responsibility and the necessity to take fast decisions is associated with the perception of more stress. Consistent with these results, deck and engine officers should achieve a greater self-control than the crew. These data are consistent with the findings of other studies in the same population groups [30], suggesting that management responsibility is more often associated with higher levels of stress. Lack of career perspectives and the monotony of the work on board mainly belong to the lower categories of seafarers [30] and this can be another source of stress. This probably explains why chief stewards/catering staff represent the working group with the lowest vitality. No significant differences were found among the other groups of workers.

The overall stress index was found to be rather low in the majority of the interviewed seafarers, and only $3 \%$ of them were affected by a severe distress. Collectively, our results are different from those reported by literature [26], as in our sample a lower distress occurrence was observed. This aspect may depend from the characteristics of our sample and probably from the attention the shipping company has to the conditions on board of their ships, and on the on board work organisation.

Our data suggest that shipping companies should be involved in specific activities for lowering as much as possible the modifiable factors leading to stress. The improvement of on board conditions could significantly reduce distress of workers and their psycho-emotional strain. Seafarers with "severe distress" should be followed up carefully and specific interventions in their favour should be undertaken. A serious question to ask is whether it is appropriate that these crew members continue to be on board. Another matter to discuss should be the introduction of a basic psychological evaluation in the guidelines on the medical examinations of seafarers.

We are aware that our work has strengths and limitations. A strength is the administration of the questionnaire while examined individuals were on board and therefore our investigation is one of the very few studies performed "on the field" [26]. This probably has allowed a more objective and direct measure of the problems under evaluation, but may have limited the number of interviewed individuals. The relatively small sample we have investigated, as well as the absence of a measured correlation between the PGWBI questionnaire and other validated measures of stress represents inversely a limitation. A strength is the administration of the questionnaire while on board, that is in the workplace, and not in the different context of the doctor's clinic. This has allowed a more objective and direct measure of the distress and then a more reliable evaluation. However, this methodology may limit the number of interviewed individuals. Further studies should be made to evaluate these aspects. We are also aware that the questionnaire fails to tap all the aspects inherent to existential condition of seafarers. It cannot be excluded that some of them may have been neglected or under evaluated. This probably is the consequence of adapting a "non-specific" questionnaire to a "specific" population as seafarers. The choice, as already mentioned in the introduction, was motivated by the simplicity of the questions, the intuitiveness of the Likert scale, and the validation of the questionnaire in other contexts.

In spite of the above limitations, the PGWBI questionnaire is a reasonable compromise for obtaining a global evaluation of psychological conditions of seafarers. New, future, actions should consider specific actions for workers showing more severe stress. These can include the availability of web communications and a system of counseling and support at distance if necessary. 


\section{CONCLUSIONS}

The results of our study suggest that improvements in providing some leisure activities, the availability of web communications and the system of counseling and support at distance if need arises, would contribute to increase the mental well-being of seafarers, a category of workers often neglected in terms of attitudinal assessments and analysis of the degree of their psychological needs.

"Our ideal should not be the calm, that changes the sea into a swamp, nor the black hurricane, but the big and strong Aliseo, full of impetus and strength, healthy and vital: an eternal and constant breath of air" [31]. With this wish in mind, research may contribute practically to provide better setting to seafarers.

\section{ACKNOWLEDGEMENTS}

The authors thank the Finaval Group SpA (Rome, Italy) for their availability and the invaluable collaboration to this study. We are greatly indebted to Captain Fabrizio Mazzucchi, Crew Manager of Finaval SpA for the useful discussions and the support in all phases of this study, and to Dr Virgilio Costanzo of Italian Ministry of Health for his suggestions. The collaboration of Masters of M/T Isola Bianca, Isola Celeste, Isola Corallo, Neverland, Neverland Angel (contributing to 2 questionnaires with different crews), and Neverland Dream in stimulating their crews to participate in the survey and in distributing and explaining if necessary the PGWBI test is gratefully acknowledged.

\section{REFERENCES}

1. Jeżewska M, Leszczyńska I, Jaremin B. Work-related stress at sea self estimation by maritime students and officers. Int Marit Health 2006; 57: 1-4.

2. Leszczyńska I, Jeżewska M, Jaremin B. Work-related stress at sea. Possibilities of research and measures of stress. Int Marit Health 2008; 59: 93-102.

3. Lazarus RS, Folkman S. Stress, appraisal and coping. Springer Publishing Co, New York 1984.

4. Widerszal-Bazyl M. Work-related stress and health. CIOP-PIB, Warszawa 2003.

5. Sundby P. Occupation and insanity. Acta Psychiatr Scand 1958; 25 (suppl. 106): 276-287.

6. Tenfjord OW. Mental diseases among Norwegian seamen. Biul Inst Med Morsk Gdansk 1966; 17: 373-377.

7. Anna-Lilsa E. Health and stress of seafarers. Scand J Work Environ Health 1985; 11: 427-432.

8. Carotenuto A, Molino I, Fasanaro AM, Amenta F. Psychological stress in seafarers: a review. Int Marit Health 2012; 63: 188-194.

9. Oldenburg M, Baur X, Schlaich C. Occupational risks and challenges of seafaring. J Occup Health 2010; 52: 249-56.

10. Shultz DP, Shultz S. Psychology and challenges of the present-day work. PWN, Warszawa 2002.

11. Kahn RL, Byosiere P. Stress in organization. In: Dunette WM, Hough L eds. Handbook of industrial and organizational psychology. Consulting Psychologist Press (Paolo Alto, California) 1992; 3: 571-650.
12. Hansen HL. Surveillance of deaths on board Danish merchant ships, 1986-1993; implications for prevention. Occup Environmental Med 1996; 53: 269-275.

13. Larsson TJ, Lindquist C. Traumatic fatalities among Swedish seafarers 1984-1998. Safety Science 1992; 15: 172-3-182.

14. Szymańska K, Jaremin B, Rosik E. Suicides among Polish seamen and fishermen during work at sea. Int Marit Health 2006; 57: 36-45.

15. Cooper A. Implications of maritime globalization for the crews of merchant ships. J Marit Res 2000; 2: 1-8

16. Jaremin B, Kotulak E, Starnawska M, Tomaszunas S. Causes and circumstances of death of Polish seafarers during sea voyages. J Travel Med 1996; 3: 91-95.

17. Roberts SE, Jaremin B, Chalasani P, Rodgers SE. Suicides among seafarers in UK merchant shipping, 1919-2005. Occup Med (Lond) 2010; 60: 54-61.

18. Nielsen, D. Deaths at sea: a study of fatalities on board Hong Kong-registered merchant ships (1986-1992). Safety Science 1999; 32: 121-141.

19. Roberts SE, Judy CW. Update of mortality for workers in the UK merchant shipping and fishing sectors. Report for the Maritime and Coastguard Agency and the Department for Transport. London 2007: 578-585.

20. Roberts SE, Marlow PB. Work related mortality among merchant seafarers employed in UK Royal Fleet Auxiliary shipping from 1976 to 2005. Int Marit Health 2006; 57: 1-4.

21. Roberts SE, Marlow PB. Traumatic work related mortality among seafarers employed in British merchant shipping, 1976-2002. Occup Environmental Med 2005; 62: 72-180.

22. Iversen RT. The mental health of seafarers. Int Marit Health 2012; 63: 78-89.

23. International Labour Conference. Maritime Labour Convention (MLC) 2006. ILO, Geneva 2006.

24. Grossi E, Mosconi P, Groth N, Niero M, Apolone G. II Questionario Psychological General Well-Being. Edizioni “Mario Negri”, Versione Italiana. Milano 2002.

25. Salyga J, Kusleikaite M. Factors influencing psychoemotional strain and fatigue, and relationship of these factors with health complaints at sea among Lithuanian seafarers. Medicina (Kaunas) 2011; 47: 675-681.

26. Oldenburg M, Hogan B, Jensen $H$. Systematic review of maritime field studies about stress and strain in seafaring. Inter Arch of Occup Env Health 2013; 86: 1-15.

27. Legislative Decree 9 April 2008, No. 81. Actions consequent to article 1 of the Law 3 August 2007, No. 123, on health protection and safety in working places (in Italian). Official Journal of Italian Republic 101 of 30 April 2008).

28. Jensen OC, Laursen FV, Sorensen FL. International surveillance of seafarers' health and working environment. A pilot study of the method. Preliminary report. Int Marit Health 2001; 52: 59-67.

29. Bloor M. An essay on 'health capital' and the Faustian bargains struck by workers in the globalised shipping industry. Sociology Health IIIness 2011; 33: 973-986.

30. Parker AW, Hubinger LM, Green S et al. A survey of the health, stress and fatigue of Australian seafarers. Australian Maritime Safety Authority, Canberra 1997.

31. Martinson H. "Harry Martinson - Poetry". Nobelprize.org. Nobel Media AB 2013. Web. 31 Jul 2013. http://www.nobelprize.org/ nobel_prizes/literature/laureates/1974/martinson-poems10-e.html. 